Editor's Note: These short reviews of recent JNeurosci articles, written exclusively by students or postdoctoral fellows, summarize the important findings of the paper and provide additional insight and commentary. If the authors of the highlighted article have written a response to the Journal Club, the response can be found by viewing the Journal Club at www.jneurosci.org. For more information on the format, review process, and purpose of Journal Club articles, please see http://jneurosci.org/content/ preparing-manuscript\#journalclub.

\title{
Stimulation of Individual Neurons Is Sufficient to Influence Sensory-Guided Decision-Making
}

\author{
๑Matthew J. Buchan ${ }^{1 \star}$ and $\odot$ James M. Rowland ${ }^{2 *}$ \\ 'Department of Pharmacology, University of Oxford, Oxford OX1 3QT, United Kingdom and 2Department of Physiology, Anatomy \& Genetics, University of \\ Oxford, Oxford OX1 3QX, United Kingdom \\ Review of Tanke et al.
}

To be evolutionarily successful, organisms must reliably represent the sensory world and use this information to guide decisions. The sensory component of sensory-guided decision-making is well understood in the rodent barrel cortex, a primary sensory area that receives somatotopic input from the whiskers via the thalamus. The barrel cortex contains a diverse population of genetically defined neuronal cell types that respond sparsely to single-whisker stimulation (Lefort et al., 2009); these responses can be used to discriminate the outcome of a trial in basic sensory-guided decision-making tasks (Peron et al., 2015). However, a conceptual framework describing how rodents use this sparse information to guide decisions has not been established.

A more complete model has been formulated for higher brain regions through seminal work in monkeys, in which sensory-evoked spikes are integrated across a pool of neurons until the crossing of a be-

\footnotetext{
Received April 22, 2018; revised June 20, 2018; accepted June 25, 2018. We thank Dr. Michael Kohl for providing comments on the manuscript. The authors declare no competing financial interests. ${ }^{*}$ M.J.B. and J.M.R. contributed equally to this work.

Correspondence should be addressed to either of the following: Matthew J. Buchan, Department of Pharmacology, University of Oxford, Mansfield Road, Oxford OX1 3QT, United Kingdom, E-mail: matthew.buchan@chch.ox.ac.uk; or James M. Rowland, Department of Physiology, Anatomy \& Genetics, University of Oxford, South Parks Road, Oxford OX1 3QX, United Kingdom, E-mail: james.rowland@ccc.ox.ac.uk.

DOI:10.1523/JNEUROSCI.1026-18.2018

Copyright $\odot 2018$ the authors $\quad 0270-6474 / 18 / 386609-03 \$ 15.00 / 0$
}

haviorally relevant threshold, at which point a decision is made (Gold and Shadlen, 2007; Brody and Hanks, 2016). Further theoretical work has shown that weighting the inputs of individual neurons within such a "decision pool" according to their sensitivity to sensory stimuli is an optimal strategy upon which to base decision-making (Haefner et al., 2013). However, questions remain regarding the size and diversity of this pool and the relative contribution of individual neurons to its output.

Models of decision-making in monkeys generally rely on choice probability (CP), a quantitative measure of decisionmaking stemming from the observation that the activity of individual cortical sensory neurons correlates with behavioral choice (Britten et al., 1996). High CP values indicate that the outcome of a given trial can be reliably predicted from the spike count of the recorded neuron. However, the contribution of individual neurons cannot be inferred from CP alone. Correlations in response variability between neurons can contribute to a high CP value (Shadlen et al., 1996; Nienborg et al., 2012; Haefner et al., 2013). Therefore, one cannot be certain that $\mathrm{CP}$ in decision-pool models is dictated by the contribution of individual neurons rather than interneuronal correlations.

One can establish causality between neuronal activity and sensory-guided de- cision-making through direct manipulation of neurons during the presentation of sensory stimuli. The barrel cortex is an ideal model for such experiments. Because of its superficial location and somatotopic organization, it can be easily accessed with electrical or optical stimulation and its sensory input can be tightly controlled.

Previous experiments in rodents suggest that individual neurons influence behavioral response to sensory stimuli with a weight that depends on their tuning properties, in line with theoretical predictions (Romo et al., 2000; Houweling and Brecht, 2008; Doron et al., 2014). However, proximity effects of the stimulating electrode or light source in such experiments can result in stimulus-driven hypersynchronous activation at the expense of natural activity dictated by functional connectivity (Stanley, 2013). In a recent article, Tanke et al. (2018) addressed some of these limitations using juxtacellular single-neuron current injection, or nanostimulation, in rat barrel cortex.

To investigate the contribution of individual neurons to sensory-guided decision-making, rats were trained to report deflection of a single whisker by licking a spout, receiving a water reward for correct responses. After establishing a threshold stimulus, Tanke et al. (2018) asked whether inducing spike trains in single barrel-cortical neurons was sufficient to enhance detection performance. 
Overall, nanostimulation did not significantly increase detection performance. Furthermore, nanostimulation alone elicited responses in only $10 \%$ of trials. Thus, on average, single-neuron nanostimulation had no significant effect on the detection of whisker deflection.

Because neuronal heterogeneity in the barrel cortex suggests that neurons might have differing roles in sensory processing, Tanke et al. (2018) classified neurons based on electrophysiological properties. Clustering neurons according to actionpotential width and maximum firing rate yielded two groups: putative fast-spiking (FS) interneurons and putative excitatory neurons. Nanostimulation of FS interneurons enhanced the detection of whisker deflection, and the extent of enhancement was positively correlated with interspikeinterval variance, suggesting that nanostimulation of spontaneously irregular FS interneurons more reliably increased detection performance. In contrast, nanostimulation of putative excitatory neurons as a whole did not affect detection. Therefore, these neurons were further subdivided by cluster analysis based on spike count after whisker deflection. This yielded four subgroups: neurons whose activity decreased, neurons whose activity sharply increased (indicating high sensitivity), neurons whose activity weakly increased, and neurons whose activity was unchanged after whisker deflection. Nanostimulation of highly sensitive neurons significantly enhanced the detection of whisker deflection. There were no significant effects in the remaining subgroups.

These results suggest that the activity of a small population of highly sensitive (HS) neurons belonging to the sensoryguided decision pool have a disproportionately large impact on the detection of whisker deflection. To estimate the size of this pool, Tanke et al. (2018) used the recorded responses of HS neurons to construct a simple threshold detection model. A pool size of $\sim 10$ HS neurons closely matched their observed estimates of detection enhancement evoked by nanostimulation. The authors conclude that single-neuron nanostimulation of either putative FS interneurons or HS neurons was sufficient to increase the amount of evidence for whisker motion provided to the sensory-guided decision-making pool, thereby enhancing detection. This observation provides welcome insight regarding the influence of individual neurons upon sensory-guided decision-making.

Several findings by Tanke et al. (2018) are consistent with currently available lit- erature. Previous studies have shown that the influence of individual neurons on sensory-guided decision-making increases with stimulus sensitivity (Houweling and Brecht, 2008). Furthermore, the location and electrophysiological properties of recorded HS neurons suggest that they correspond to layer 5b pyramidal neurons (de Kock et al., 2007), which account for the majority of intracortical output (Harris et al., 2018); hence, stimulation of these neurons is likely to have a significant impact on global brain networks and may influence behavior more strongly than locally connected neurons.

In contrast, the finding that nanostimulation of single FS interneurons enhances stimulus detection is unexpected. Previous work has shown that barrel cortex parvalbumin-expressing (PV) interneurons, which are likely the main constituent of the putative FS group (Markram et al., 2004), fired less in trials in which strong whisker motion was detected than in those in which it was not. Additionally, stimulus detection was enhanced or reduced when PV interneurons in layer $2 / 3$ were optogenetically inhibited or stimulated, respectively (Sachidhanandam et al., 2016). These seemingly contradictory results may be explained by the timing of stimulation. Tanke et al. (2018) began nanostimulation concurrent to whisker stimulus onset, whereas Sachidhanandam et al. (2016) incorporated an $80 \mathrm{~ms}$ delay. The incorporation of a delay may mean that any postinhibitory effects induced by Sachidhanandam et al. (2016), such as long-lasting ( $\leq 0.4 \mathrm{~s})$ biphasic depolarizations (Yamashita and Petersen, 2016), fall outside a critical window for detection of whisker motion. Additionally, Sachidhanandam et al. (2016) restricted their stimulation to neurons in layer $2 / 3$. Given the functional heterogeneity of neuronal subtypes across layers and within circuits (Harris and Shepherd, 2015), it is reasonable to suppose that the effects of nanostimulation differ across layers.

One way individual PV neurons might enhance detection of threshold whisker deflection is by increasing network signalto-noise ratio. Nanostimulation of PV interneurons could achieve this in several ways. First, stimulation of FS interneurons might increase whisker-evoked neural responses relative to ongoing activity, leading to greater salience of whisker stimulation, much as optically driving PV interneurons in auditory cortex suppresses spontaneous network activity, but not responses evoked by a tone (Hamilton et al., 2013). Second, stimulation of PV interneurons might drive gamma oscillations, dampen network noise, and increase the gain of spike trains, as has been seen with optical stimulation of PV interneurons in slices from rodent PFC (Sohal et al., 2009). Increased signal-to-noise ratio may also account for the finding that irregularly firing FS interneurons more reliably enhanced whisker detection. The electrical stimulation performed by Tanke et al. (2018) causes bursts of spikes, thus transitioning the neuron from irregular to regular firing. This transition would result in a greater increase in signal-to-noise in spontaneously irregular neurons relative to spontaneously regular neurons, thereby potentially ascribing greater saliency.

Another way individual neurons might enhance detection of threshold whisker deflection is through the modulation of global brain state. Driving single neurons in wholecell patch configuration in vivo modulates local field potential and switches the cortex into a persistent up state ( $\mathrm{Li}$ et al., 2009). Hence, nanostimulation by Tanke et al. (2018) might have had effects beyond the local circuit of the targeted neuron. Additionally, in vivo optical stimulation of PV interneurons in barrel cortex induces gamma oscillations and modulates whisker-evoked responses (Cardin et al., 2009). Driving an opsin restricted to PV interneurons reduced spike latency from whisker stimulation and improved the spike precision of these responses. This effect varied depending on the timing of the whisker-evoked response relative to PV-interneuron-induced gamma oscillations. These findings illustrate how the nanostimulation of individual FS interneurons by Tanke et al. (2018) may have driven salient changes in global brain state during sensory decision-making.

Finally, it is also possible that the detection enhancement reported by Tanke et al. (2018) is caused by nanostimulation of vasoactive intestinal peptide-expressing (VIP) interneurons, which inhibit other interneurons and thus disinhibit excitatory neurons (Lee et al., 2013). Because VIP neurons are sparse in barrel cortex and are predominantly localized to layer 2/3, Tanke et al. (2018) state that the FS group is unlikely to include VIP interneurons. Disinhibition cannot be ruled out entirely, however, because suppression of layer $4 \mathrm{PV}$ interneurons has been shown to result in a tightly coupled increase in both excitatory and inhibitory inputs to downstream excitatory neurons (Moore et al., 2018).

In conclusion, the work of Tanke et al. (2018) constitutes an important step toward 
establishing a conceptual framework for the role of sparse barrel cortex activity in sensory-guided decision-making in rodents. It illustrates how neurons can play specific roles in sensory-guided behavior. Furthermore, the finding that a small number of neurons can influence behavioral choice in response to sensory stimuli provides an excellent basis for exploring the role of individual neurons in decision-making more generally.

\section{References}

Britten KH, Newsome WT, Shadlen MN, Celebrini S, Movshon JA (1996) A relationship between behavioral choice and the visual responses of neurons in macaque MT. Vis Neurosci 13:87-100. CrossRef Medline

Brody CD, Hanks TD (2016) Neural underpinnings of the evidence accumulator. Curr Opin Neurobiol 37:149-157. CrossRef Medline

Cardin JA, Carlén M, Meletis K, Knoblich U, Zhang F, Deisseroth K, Tsai LH, Moore CI (2009) Driving fast-spiking cells induces gamma rhythm and controls sensory responses. Nature 459:663-667. CrossRef Medline

de Kock CP, Bruno RM, Spors H, Sakmann B (2007) Layer- and cell-type-specific suprathreshold stimulus representation in rat primary somatosensory cortex. J Physiol 581: 139-154. CrossRef Medline

Doron G, von Heimendahl M, Schlattmann P, Houweling AR, Brecht M (2014) Spiking irregularity and frequency modulate the behavioral report of single neuron stimulation. Neuron 81:653-663. CrossRef Medline

Gold JI, Shadlen MN (2007) The neural basis of decision-making. Annu Rev Neurosci 30:535574. CrossRef Medline

Haefner RM, Gerwinn S, Macke JH, Bethge M (2013) Inferring decoding strategies from choice probabilities in the presence of correlated variability. Nat Neurosci 16:235-242. CrossRef Medline

Hamilton LS, Sohl-Dickstein J, Huth AG, Carels VM, Deisseroth K, Bao S (2013) Optogenetic activation of an inhibitory network enhances feedforward functional connectivity in auditory cortex. Neuron 80:1066-1076. CrossRef Medline

Harris JA, Mihalas S, Hirokawa KE, Whitesell JD, Knox J, Bernard A, Bohn P, Caldejon S, Casal L, Cho A, Feng D, Gaudreault N, Gerfen C, Graddis N, Groblewski PA, Henry A, Ho A, Howard R, Kuan L, Lecoq J, et al. (2018) The organisation of intracortical connections by layer and cell class in the mouse brain. bioRxiv 292961.

Harris KD, Shepherd GM (2015) The neocortical circuit: themes and variations. Nat Neurosci 18:170-181. CrossRef Medline

Houweling AR, Brecht M (2008) Behavioural report of single neuron stimulation in somatosensory cortex. Nature 451:65-68. CrossRef Medline

Lee S, Kruglikov I, Huang ZJ, Fishell G, Rudy B (2013) A disinhibitory circuit mediates motor integration in the somatosensory cortex. Nat Neurosci 16:1662-1670. CrossRef Medline

Lefort S, Tomm C, Floyd Sarria JC, Petersen CC (2009) The excitatory neuronal network of the C2 barrel column in mouse primary somatosensory cortex. Neuron 61:301-316. CrossRef Medline

Li CY, Poo MM, Dan Y (2009) Burst spiking of a single cortical neuron modifies global brain state. Science 324:643-646. CrossRef Medline

Markram H, Toledo-Rodriguez M, Wang Y, Gupta A, Silberberg G, Wu C (2004) Interneurons of the neocortical inhibitory system. Nat Rev Neurosci 5:793-807. CrossRef Medline

Moore AK, Weible AP, Balmer TS, Trussell LO, Wehr M (2018) Rapid rebalancing of excita- tion and inhibition by cortical circuitry. Neuron 97:1341.e6-1355.e6. CrossRef Medline

Nienborg H, Cohen MR, Cumming BG (2012) Decision-related activity in sensory neurons: correlations among neurons and with behavior. Annu Rev Neurosci 35:463-483. CrossRef Medline

Peron SP, Freeman J, Iyer V, Guo C, Svoboda K (2015) A cellular resolution map of barrel cortex activity during tactile behaviour. Neuron 86:783-799. CrossRef Medline

Romo R, Hernández A, Zainos A, Brody CD, Lemus L (2000) Sensing without touching: psychophysical performance based on cortical microstimulation. Neuron 26:273-278. CrossRef Medline

Sachidhanandam S, Sermet BS, Petersen CC (2016) Parvalbumin-expressing GABAergic neurons in mouse barrel cortex contribute to gating a goal directed sensorimotor transformation. Cell Rep 15:700-706. CrossRef Medline

Shadlen MN, Britten KH, Newsome WT, Movshon JA (1996) A computational analysis of the relationship between neuronal and behavioral responses to visual motion. J Neurosci 16:1486-1510. CrossRef Medline

Sohal VS, Zhang F, Yizhar O, Deisseroth K (2009) Parvalbumin neurons and gamma rhythms enhance cortical circuit performance. Nature 459:698-702. CrossRef Medline

Stanley GB (2013) Reading and writing the neural code. Nat Neurosci 16:259-263. CrossRef Medline

Tanke N, Borst JG, Houweling AR (2018) Single-cell stimulation in barrel cortex influences psychophysical detection performance. J Neurosci 38:2057-2068. CrossRef Medline

Yamashita T, Petersen CC (2016) Target-specific membrane potential dynamics of neocortical projection neurons during goal-directed behavior. eLife 5:e15798. CrossRef Medline 